\title{
Analysis of the Role of Cultural-Creative Industries to Regional Development Using PLS Path
}

\author{
LuJie FAN \\ Weike Soft \\ Weifang Science and Technology College \\ Shouguang,Shandong, China \\ e-mail:fkke@163.com
}

\author{
Jiangxue YU \\ Department of Business Administration \\ Weifang Science and Technology College \\ Shouguang,Shandong, China \\ e-mail:ysx122@126.com
}

\begin{abstract}
With the accelerated process of globalization and the knowledge economy, cultural -creative industries in many countries or regions become the pillar industries reflecting the comprehensive competitiveness and economic and social development. Through the use of PLS path analysis, multidimensional perspective analysis of the policy implications related to how the development of culturalcreative industries affected areas and to verify the potential role for the regional development by cultural-creative industries. Starting from the interaction between culturalcreative industries and regional development, a theoretical model which reveals the role of cultural-creative industries on regional development was established.
\end{abstract}

Keywords- PLS path analysis, cultural-creative industries, regional development

\section{INTRODUCTION}

With the accelerated process of globalization and the knowledge economy, cultural and creative industries as an international division of labor and the value chain in the world, the booming, has become a new trend in the international metropolis of industrial development. Cultural and creative industries by culture, technology, creativity combine to drive the development of related industries, as many countries or regions to improve the comprehensive competitiveness, and promote economic and social development of pillar industries. However, how the role of cultural and creative industries in urban development? Thus should be how to effectively promote the development of cultural and creative industries? These are the real problems our country is currently facing the city's economic development.

\section{PLS PATH MODEL TO ESTABLISH CULTURAL AND CREATIVE INDUSTRIES ON REGIONAL DEVELOPMENT}

\section{A. PLS model}

Cultural-creative industries own industry characteristics determine its special position in the national economic system, and it has gone beyond the single dimension of the impact of other industries for economic growth. It appears that the inheritance of the study of economic growth has become more complex, innovative mechanisms, diffusion mechanism, transformation mechanism set up its own evolutionary path of cultural and creative industries to economic growth and the spirit of the internal mechanism of the product, and through this evolutionary path The result is precisely the important factors that influence economic growth. Therefore, from this idea that we can associate model cultural and creative industries and regional economic growth, cultural and creative industries in the direct path of economic growth, by adding a number of mediating variables, which include technological innovation, cultural capital, human capital three production factors, thus affecting the economic growth path for the interpretation of cultural and creative industries framework of a new model. Path model established cultural and creative industries to economic growth impact of structural model contains latent variables (LV) and the significant variables (MV), the model has five LV, including the development of cultural and creative industries, cultural values, human capital technological innovation and economic growth levels. Among them, the development of cultural and creative industries as exogenous latent variables, cultural values, human capital, technological innovation capacity of endogenous latent variables, the level of overall economic growth model centered on the latent variables. The indicators for each latent variable model, also known as measurable variables, as shown in the table and are used to reflect type indicator. PLS path indicator system analysis model is shown in the table I.

\section{B. Model Construction}

Model design (as figure 1), a total of seven basic assumptions are:

H1: the development of cultural and creative industries to economic growth has a direct positive role in promoting.

$\mathrm{H} 2 \mathrm{a}$ : the development of cultural and creative industries to promote technological innovation and knowledge accumulation.

$\mathrm{H} 2 \mathrm{~b}$ : The stronger the technological innovation capability and knowledge accumulated more faster economic growth.

H3a: cultural and creative industries to form a people's values have a positive role in promoting.

$\mathrm{H} 3 \mathrm{~b}$ : cultural values and economic development to adapt to significantly improve the speed of economic growth.

$\mathrm{H} 4 \mathrm{a}$ : cultural and creative industries to promote human capital formation and orange tired.

H4b: Human capital is an essential element conducive to economic growth. 
TABLE I. PLS PATH INDICATOR SYSTEM ANALYSIS MODEL

\begin{tabular}{|c|c|}
\hline $\begin{array}{c}\text { Latent } \\
\text { Variables }\end{array}$ & Significant variables can be measured \\
\hline \multirow{3}{*}{$\begin{array}{l}\text { Development } \\
\text { of cultural- } \\
\text { creative } \\
\text { industries }\end{array}$} & Number of cultural practitioners (c1) \\
\hline & City Cinemas quantity (c2) \\
\hline & Urban per capita volume of books (c3) \\
\hline \multirow{4}{*}{$\begin{array}{l}\text { Levels } \\
\text { economic } \\
\text { growth }\end{array}$} & Comprehensive long-term economic growth (e1) \\
\hline & Comprehensive income per capita (e2) \\
\hline & Industrial output value above the limit (e3) \\
\hline & GDP per capita (e4) \\
\hline \multirow{4}{*}{ Human capital } & Human Resources quantity index (h1) \\
\hline & HR mass index (h2) \\
\hline & Human resource allocation index (h3) \\
\hline & Human Resource Education Index (h4) \\
\hline \multirow{3}{*}{$\begin{array}{l}\text { Technological } \\
\text { innovation } \\
\text { capability }\end{array}$} & Technological strength index (t1) \\
\hline & Technology Innovation Capability Index (t2) \\
\hline & Technology transformation capability index (t3) \\
\hline \multirow{4}{*}{ Cultural values } & Entrepreneurship index (v1) \\
\hline & Innovative Climate Index (v2) \\
\hline & Conduct exchanges Index (v3) \\
\hline & Humanities degree of internationalization (v4) \\
\hline
\end{tabular}

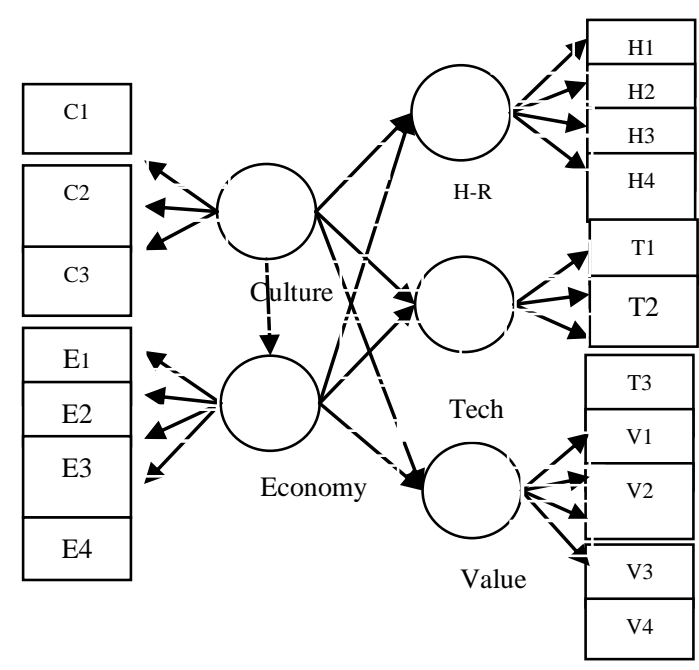

Figure 1. Path analysis model

\section{PLS PATH MODEL TO EVALUATE THE CULTURAL AND CREATIVE INDUSTRIES IMPACT ON ECONOMIC GROWTH}

In this section, select 201354 valid samples for PLS path model analysis based on a theoretical model. When the model analysis, this paper is the use of Smart PLS2.0 PLS path modeling and analysis software, computing options are as follows:

(1) Select the data using normalized (Mean $=1$, Variance $=0$ ) (2)Selection of the path weighting method (Path weighting Scheme) internal estimates

(3)The sampling method using Bootstrap estimation results of the model will be tested and evaluated

\section{A. The only dimension inspection}

After obtaining the parameters of the PLS path model, on the rationality of the model evaluation. Composite reliability coefficient $\mathrm{P}$ can be used as a measurement tool reliability coefficient. If the reliability coefficient, which means that the high internal consistency of each index, Each latent variable $\mathrm{P}$ is greater than equal to 0.7 , indicating that changes in the latent variable corresponding to at least be able to explain $70 \%$ of the change in measurement tools. That $\mathrm{P}$ bigger, more reliable measurement tools. Composite reliability coefficient is calculated as Eq.1

$$
\rho=\left(\sum_{k} \lambda_{n}\right)^{2}+\sum_{k}\left(1-\lambda_{n}^{2}\right)
$$

\section{B. Model to estimate the parameters of the test}

In this paper, the software for the price of the model SmartPLS2.0 Loading Outer Weight and Path Coefficient carried Bootstrap test. In the Bootstrap option, the paper set for each group and then sampling the same number of samples and number of samples in the initial sample, the number of re-sampling of 200 times. Bootstrap test results are shown in the table II.

TABLE II. BOOTSTRAP TEST RESULTS

\begin{tabular}{c|c|c|c}
\hline & $\begin{array}{c}\text { Sample } \\
\text { Mean }\end{array}$ & $\begin{array}{c}\text { Standard } \\
\text { Deviation }\end{array}$ & T-Statistics \\
\hline Culture->Economy & 0.679459 & 0.037753 & 17.956817 \\
\hline Culture->H-R & 0.735581 & 0.029992 & 24.418335 \\
\hline Culture->Tech & 0.868186 & 0.043769 & 20.10678 \\
\hline Culture->Value & 0.477417 & 0.038637 & 12.127505 \\
\hline H-R->Economy & 0.162411 & 0.080208 & 2.112180 \\
\hline Tech->Economy & 0.326186 & 0.103465 & 3.068498 \\
\hline Value->Economy & 0.341725 & 0.053262 & 6.481567 \\
\hline
\end{tabular}

By Excel software statistical formulas can be obtained over three test results table $\mathrm{t}$ statistic values at $95 \%$ probability, the critical value of the degree of freedom $\mathrm{df}=$ 
50 , then the ta $=2.01$ Bootstrap test results from the point of view, measured in the load factor path coefficient equation, and the external structure of the weight coefficient by the equation are the statistical test, it is considered important in these model coefficients significantly different from 0 .

\section{Average extraction rate variance}

In PLS path model, the average variance extraction rate (AVE) is the difference between the role of the external validity of the evaluation model, that is, outside of the model reflects the schema for each latent variable is equal AVE they reflect measurement the common factor variable degrees of average. In evaluating the effect of an external model, the requirements for the average extraction rate variance has two aspects, one requires AVE value greater than 0.5 , which indicates a latent variable to explain the variance of the sum of the measured variables they reflect $509 \mathrm{~b}$ or more. The average variance extracted is calculated as Eq.2:

$$
A V E=\sum_{k} \lambda_{n}^{2} /\left[\sum_{k} \lambda_{n}^{2}+\sum_{k}\left(1-\lambda_{n}^{2}\right)\right]
$$

Here, $\mathrm{k}$ represents a number of indicators of latent variables under, in h-index indicates a latent variable factor loadings. Data in the table III show that the external model in this study achieved this standard.

TABLE III. AVERAGE EXTRACTION RATE VARIANCE

\begin{tabular}{c|c}
\hline & AVE \\
\hline Culture & 0.665629 \\
\hline H-R & 0.588156 \\
\hline Value & 0.554874 \\
\hline Economy & 0.601909 \\
\hline Tech & 0.823076 \\
\hline
\end{tabular}

As shown, the results show that the discriminant validity of the condition has been well met, thus described the construction of the model in terms of the concept, there are differences from the empirical.

Finally, structural equation model based on partial least squares method, in order to reflect the extent of the merits of the model, but also the value of R2 each endogenous construct the model for analysis. In this article, all endogenous construct (level of economic growth, human capital, technological innovation and cultural values ) of R2 values are $0.67,0.53,0.77,0.22$, thus indicating structural equation model has a strong ability to predict.

According confirmatory results, we finally get the following structural equation model shown in Figure II. It can be visually displayed linkages between variables. In the road map, the one-way arrows indicate certain variables affect other variables (i.e. causality) it points, the value of each arrow is straight beside the path coefficients, i.e standardized parameter estimates. By the size of the path coefficients can see the influence of one variable to another variable size.

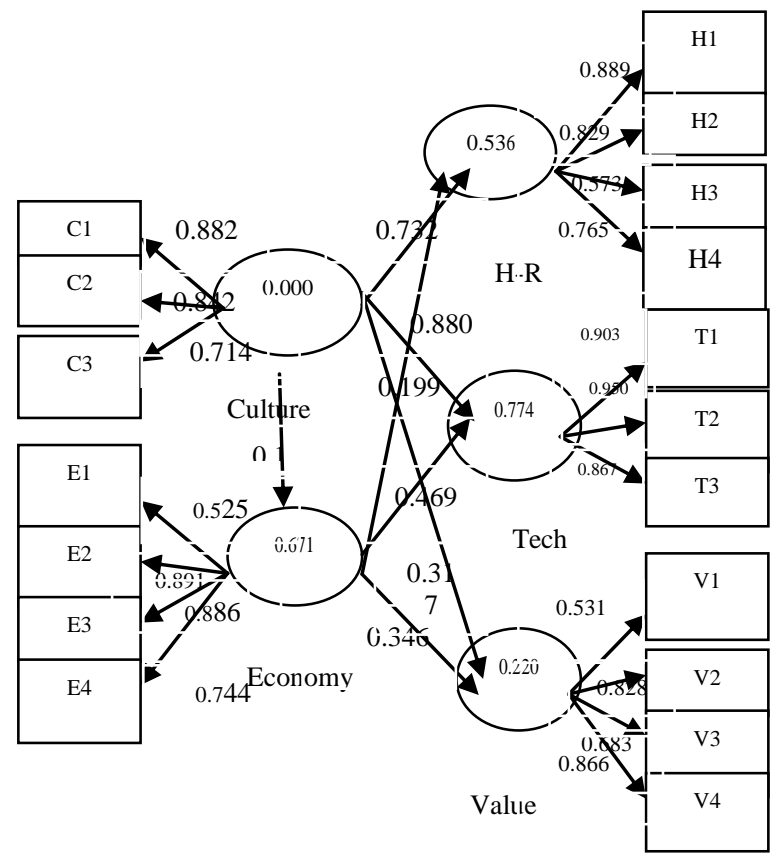

Figure 2. cultural and creative industries affect economic growth path analysis

\section{EFFECTS OF CULTURAL AND CREATIVE INDUSTRIES}

\section{A. Direct effects of cultural and creative industries}

The city is an important carrier of national and regional economic development. As can be seen from the road map, the development of China's major cities in recent years, cultural and creative industries to economic growth there is a direct impact on its direct path coefficient of 0.13 . This data is evidence that the development of cultural and creative industries do play an important role in regional economic development, economic growth in its direct effect is quite obvious.

\section{B. Path of cultural-creative industries and the impact on regional economic growth overall effect}

Paths and the effect of cultural and creative industries to economic growth as follows:

The first path is the direct path that directly affect the cultural and creative industries to economic growth, and its effect is 0.13. Development of cultural and creative industries is bound to boost the overall economic growth.

The second path, the path that is an indirect cultural and creative industries - human capital - the level of economic growth, its indirect effect $=0.732 \times 0.169=0.124$

The third path, indirect paths that cultural and creative industries - technology innovation capability - level of economic growth, its indirect effect $=0.88 \times 0.317=0.279$.

The fourth path, indirect paths that cultural and creative industries - cultural values - the level of economic growth, its indirect effect $=0.469 \times 0.345=0.162$

In summary, the total effect of cultural-creative industries indirectly, affect economic growth $=0.124+0.279+0.162=$ 0.565 , and the ratio of direct effect is 4.34 . This shows that 
economic growth brought about by the development of cultural and creative industries is much less than the direct effect of the indirect effects resulting from it, which is 4.34 times the former. Direct and indirect effects should be added to the total impact of cultural and creative industries to get the total effect of the level of economic growth, its value is 0.695 , namely the development of cultural and creative industries to enhance a percentage point each, to enhance the level of economic growth in all about 0.695 percentage points. This shows that, despite the small proportion of cultural and creative industries in the current economic system, but we can not ignore the development of cultural and creative industries, it promotes greater functionality embodied in its economic growth caused by the above effect.

\section{CONCLUSION}

Cultural and creative industries of the national economy compared to other industrial categories is still a new thing, though, it got much attention and achieved rapid development worldwide. PLS path analysis method applied in this article to verify the path of cultural and creative industries and the effects of regional economic growth, and the following conclusions:

First, the total output of the cultural and creative industries is a direct form an integral part of the national output growth. Secondly, the development of cultural and creative industries to the accumulation of human capital, to shape cultural values, supporting technological innovation has a direct positive effect. In addition, human capital, cultural values, economic growth, technological innovation is the main influence factors of production. Cultural and creative industries with innovative mechanisms, and thus the above structural factors of production optimization and adjustment, indirectly promote the growth level of the national economy, fully reflects the potential role of cultural and creative industries.

\section{ACKNOWLEDGMENT}

This work was financially supported by Economic and Information Technology Commission of Shandong, (Issue No. 2014-053).

\section{REFERENCES}

[1] Howkins.J. The Creative conomy: How People make from ideas. America:Allen Lane the Penguin Press.2001

[2] Florida R L. The rise of the creative class:how it's transforming work,leisure, ommunity and everyday life [M]. Basic Civitas Books. 2002

[3] Banks Mark. Craft Labor and Creative Industries[J].International Journal ofCultural Policy: 2010. 16 (3): 305-321

[4] Richard Florida. Cities and the creative class [M]. NewYork: Rouledge.2005

[5] PaoloGuerrieri,Valentina, Meliciani. Technology and Internation and Competitiveness: The Inter dependence between Manufacturing and ProducerCreative Industry $[\mathrm{J}]$. StructuralChange\&Economic Dynamics: 2005(12): 109-128

[6] Joreskog K G, Sorbom D. LISREL 8User'sReferenceGuide[M] Chicago:ScientificSoftware International. 1996

[7] West S G, Finch JF, Curran PJ. Structuralequation models withnon-normal variables: problems and remedies[C]//HoyleR H. StructuralEquationModeling. Thousand Oaks. CA. 1995:56-75

[8] McDonald R P, HoMR. Principles and practices in reporting structuralequationanalysis[J]. Psychological Methods: 2002,7: 64-82. 